\title{
A WEEK IN HOSPITAL: A GP LEARNING EXPERIENCE
}

\author{
Morna Murgatroyd, GP \\ Meadowside Surgery, Lancaster
}

\section{INTRODUCTION}

General practitioners try to keep up to date with the latest developments in medicine, so that they can give the best care to their patients. The government introduced the controversial contract for GPs in 1990 and if we attend educational meetings in a variety of medical subjects, an allowance is given to cover expenses.

This applies to principals only, as non-principals are expected to finance and motivate themselves. There are soon to be changes again when practice-based accreditation is introduced.

\section{HOW DO GPS OBTAIN THEIR SO-CALLED "BROWNIE POINTS"?}

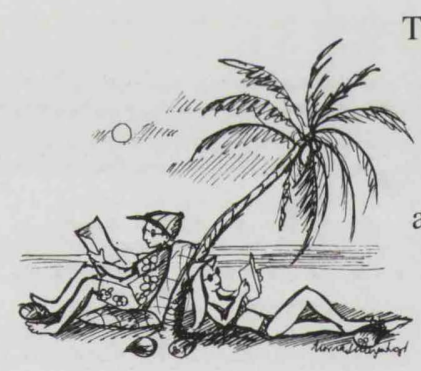

combine travel and leisure
The Lancaster postgraduate medical centre holds frequent lunchtime and evening meetings, which have been educationally approved. These are an easy way to learn and GPs find it helpful to meet with colleagues who work in primary and secondary care. GP home visiting is often done at lunchtime and so are multidisciplinary, educa-tional and practice meetings; evening surgeries sometimes run late, and then there are on-call duties, so GPs may find it hard to attend these meetings. Some combine travel and leisure and venture far from home to gain the necessary accreditation. Courses are advertised in medical journals every week. If you spend a few days away from the practice you could arrive back to a mountain of family washing at home and a tray full of paper at work. Suddenly you feel you have never been away and you are back into the old routine.

\section{HOW MUCH DO WE REMEMBER ABOUT LECTURES?}

Notes written about lectures or groupwork are too easily filed away 'to look at one day when I get a minute'. I went away on a GP course two years ago. What do I remember about it? I remember that it was held in a hospital about a hundred miles away. The weather was bitterly cold and it snowed in mid-March. There was a lecture by Dr Derek Doyle and I bought his book on domiciliary palliative care. I also bought the James Willis book "The Paradox of Progress", which I thoroughly recommend. There was a wonderful talk, voted the best on the course, on medical ethics by Professor Graham of Aberdeen. The tragic news of the deaths of the primary school children and their teacher who were shot in Dunblane came to us on 13th March 1996 and was the saddest day of all. When I returned to work some patients found it helpful to share their emotions about this event.

\section{WEAKNESS AND GAPS IN KNOWLEDGE}

Later that year I took the MRCGP exam (a quarter of a century after qualifying) and was forced to face up to my weaknesses and the gaps in my knowledge. If you want a true learning experience, try viewing your consultations. A few weeks later you will never be the same again.

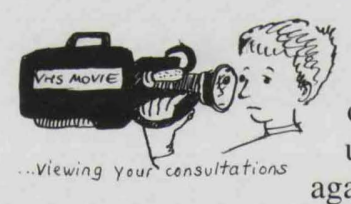

Last October I had five days of study leave provisionally earmarked on the practice calendar for a GP update course, away from Lancaster again. I liked the course content and felt confident in some subjects. I knew I would enjoy it and would not find it challenging. But would it address my educational needs? How much of the information would I make use of in everyday practice? Would it benefit the practice and my patients?

Shortly before the proposed study leave I decided not to go away. I told Sarah Brear, the GP tutor, about my ideas for a personal education plan. I already had a list of the things I needed to know more about and with the help of my hospital colleagues, we devised a timetable for my course. My aim was to update my knowledge and receive personal tuition on:

- radiological procedures, because patients who were waiting for specialised radiological procedures such as CT scans had asked me what would happen to them and I had never witnessed these procedures

- gynaecological procedures, because a memo from the gynaecology department had stated that GPs should be able to tackle pipelle sampling and I had never seen this done. I had not seen hysteroscopy or colposcopy either

- red eyes, because patients frequently present to us with red eyes. Is the diagnosis conjunctivitis, iritis or glaucoma?

- diabetes, because an insulin-dependent diabetic patient of ours had recently become hypoglycaemic at $2.30 \mathrm{am}$. I visited and the intravenous glucose treatment I gave worked, but I then found it difficult to sort out the rest of her day's insulin requirement without the advice of the diabetic nurse 
- joints, because I refer more joint problems to specialists than my partners do, due to my unfamiliarity with joint examination

- heart failure, because ACE inhibitors and calcium channel blockers still mystify me and I am wary of their side effects

- finally, I was also hoping to meet some of the newlyappointed consultant staff. This would help me to feel more confident when speaking on the telephone about patients' problems.

\begin{tabular}{|l|l|l|l|}
\hline Day & am & pm & evening \\
\hline Mon & eye outpatients & hysteroscopy clinic & difficult joints \\
\hline Tues & barium list & nuclear medicine & - \\
\hline Wed & diabetic clinic & $\begin{array}{l}\text { Dexa scanning } \\
\text { colposcopy clinic }\end{array}$ & - \\
\hline Thurs & $\begin{array}{l}\text { trauma clinic } \\
\text { ultrasound }\end{array}$ & $\begin{array}{l}\text { rheumatology } \\
\text { Kendal }\end{array}$ & - \\
\hline Fri & nuclear medicine & medical outpatients & - \\
\hline
\end{tabular}

\section{TIMETABLE}

This was devised simply by going to the relevant departments and speaking to the consultants or their secretaries. They were extremely helpful and enthusiastic. My timetable was dictated by fixed outpatient days and time. I wanted to fit in some practice meetings and my Clinical Assistant sessions at the day hospital as well. It was beginning to look like an intensive week of work.

\section{DAY BY DAY}

Monday I went to Mr Khanna's eye outpatients before it moved to the new premises. I was hoping to find out more about red eyes. Before the clinic started Mr Khanna was drawing me a picture of the eyeball to help me with the detailed anatomy. We discussed the identification of conjunctivitis, iritis, glaucoma, normal tension glaucoma and ocular hypertension. Information which I found particularly useful included:

- patients with acute iritis should be referred to the eye ward

- chloramphenicol eyedrops are very unlikely to cause side effects if the naso-lacrimal duct is pressed as the drops are applied, to prevent stomach absorption

- patients need time to become familiar with the visual field test

- patients who visit the clinic need to be advised that at their appointment they will be having eye drops which will alter their vision so they should not drive to the appointment as they will not be able to drive back.

At the clinic I saw a young man with iritis who had steroid injections to the eyes, a naso-lacrimal washout, patients with cataracts, patients with floaters, and pterygium. This may occur more frequently in areas of dust and heat or lack of ozone layer. I also saw a patient with raised intraocular pressure, a Shirmer test being done for a patient with dry eyes, retinal detachment, and macular degeneration and pigmented areas in the retina.
We discussed helpful things for GPs to write in the referral letters - "please see enclosed GOS 18" is not quite enough. Of particular interest would be any history of diabetes, heart disease and hypertension, chest diseases, allergies, current medication and recent illness.

The clinic was busy and the room was dark. The nurse came in and out of the room frequently. Consultations were quiet and required intense concentration. Most patients asked very few questions and remained silent throughout when things were being explained to them about their condition.

On Monday afternoon I went to the hysteroscopy clinic. The room is small with a desk and examination couch and a monitor screen near the head end of the couch. It became very cramped when there was $\mathrm{Mr}$ Burch, two assisting nurses, an elderly patient, the patient's daughter and myself in there. Patients have already received a leaflet about hysteroscopy before the clinic. The current definition of postmenopausal bleed is any bleed one year after the last menstrual period.

A pelvic examination was performed first. The patients did not find the passage of the scope painful; one nurse stayed "top end" whilst the other assisted Mr Burch. I watched the pipelle sampling of the endometrium. I had heard that this procedure was something that a GP should be able to perform in the surgery. The pipelle was like a long tapering plastic straw that was moved in a sweeping fashion round the endometrium. Sometimes a good tube of bloody material was extruded from the pipelle onto a gauze square and then to the histology bottle.

A picture of the endometrium appeared on the monitor something I had never seen before. It was fascinating to view the entrance to the Fallopian tubes.

The patient went to dress and returned to the room, by which time all the equipment had been removed. The patient was told the findings there and then, but any samples taken awaited histology reporting and this would be mentioned in the letter to the GP at a later date. No follow-up was arranged for most people. Hysteroscopy was not possible for one elderly lady and she was offered a future inpatient stay and general anaesthetic. One patient had thrush and was asked to get a prescription from her GP to treat it. The whole consultation took about 30 minutes.

I learned that pipelle sampling would be hard for me to do, and I would not be confident of negative findings. Patients found the procedure quick and reassuring. GPs can help by asking patients to keep a period diary for as long as possible in advance of an apppointment, and by explaining the procedure. Since I observed the clinic, I now find that I would value a letter faxed to the surgery about these procedures on the same day, as very occasionally a patient requires an urgent apppointment for sudden bleed and it is helpful to have had the information.

To finish off the day I went to a 'difficult joints' meeting at the postgraduate medical centre and met the specialists who were discussing two patients who had been invited to attend. It was good to meet my colleagues from the orthopaedic and rheumatology departments, although I think they were a bit surprised to see a GP at the meeting. The level of discussion was far beyond my knowledge - complicated surgical procedures and detailed anatomy of the wrist and ankle joints. 
Tuesday This was spent observing the barium list and nuclear medicine. Dr Flanagan introduced me to the staff and my jacket was exchanged for an X-ray protective heavy tabard. I saw a nine-year-old girl from the children's ward having a barium swallow as a day case for suspected reflux. She seemed to enjoy all the extra attention she received. I also saw a patient with known diverticular disease having a barium enema to exclude carcinoma - "It was better than my last one" - and a baby with reflux who coped brilliantly and drank the barium and seemed keen for more seemed keen for more! I was interested to see how great care was taken to put patients at their ease, how I was not made to feel in the way, how parents were welcomed into the room and the staff talked patients through the tests. Tests were producing immediate results that were visible to the radiologist and myself. Patients were not told any results at the time, to allow careful evaluation and reporting. Patients were moved and tipped gently on the examination table in various directions to allow the barium to flow. Dr Flanagan waited until he obtained the views he needed for a good record and for reporting, then the patient could go. Whilst all this was going on he was going from room to room checking various tests that were underway. I watched CT brain scans

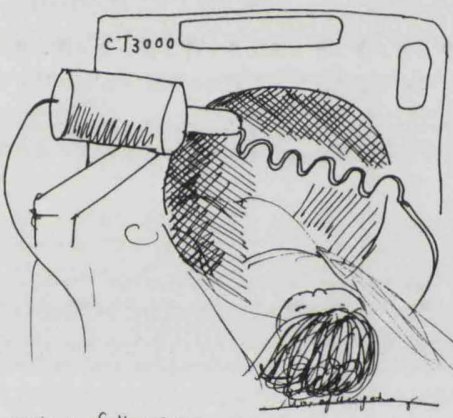

a view of the CT scanner and thought that I would be able to reassure my patients that the test itself was not stressful or frightening. The patient lay on the 'table' and the radiographers explained everything. They never missed a vein for the intravenous injections of contrast medium. The CT pictures were so clear this surprised me and I felt I could have been looking at pictures straight from Gray's Anatomy.

Wednesday On Wednesday I went to the old medical outpatients to learn more about diabetes. Sister McCaskie demonstrated a new compact home blood glucose monitoring kit that she gives to patients. I met Zoe Smith, the diabetic nurse; Jenny Lowe, who was in the process of setting up the Morecambe Bay Diabetic Register; Paul Dunstan, a dietician, and the Eli Lily rep, who happened to be there too. Unfortunately I had not realised it was audit day for the consultant staff and no patients had been booked but it was useful to meet some of the team.

At lunchtime I spent a short session with Cathi Greenbank, the senior radiographer at the Dexa scan department. Patients are sent a reassuring letter about the test and a detailed map of how to find the department The atmosphere was relaxed and quiet. The test costs around $£ 80$ and uses one tenth of the radiation of a chest X-ray. When the patient arrived, Cathi took a history about obstetric and gynaeco-logical matters, smoking and alcohol status, medication, exercise, history of fracture and past relevant diseases. The procedure is simple and takes less than 30 minutes. Patients remain fully clothed. The results are available on screen, and it must be tempting to tell the patient the outcome there and then. The radiographer maintains a high professional stance. The patient was told that the result would be sent to her GP in two or three weeks, when it had been reported on by the consultant. There were many leaflets about osteoporosis available and I picked up about six different ones.

In the afternoon I went to the colposcopy clinic. The patient will have waited about six weeks for this appointment and will be nervous and scared, because her last smear was not completely normal. A leaflet I have seen, "About Colposcopy", says "this does not mean you have cancer - it is very unlikely - colposcopy is to prevent cancer" and "the colposcope. . . is lit up and this is between your legs. The only thing you feel inside is exactly the same as when you had the smear". It must seem a bit worrying to the reader.

I met Dr Jean McCafferty, a clinical assistant in obstetrics and gynaecology, and was introduced to each patient as she came in. Patients were quickly put at ease by a methodical history-taking and a simple explanation of the test. The cervix appears on the monitor enlarged to about the size of a small pink melon. The patient had the option of seeing this and witnessing the taking of her smear. It was a very clear picture. The response was generally one of great interest.

The monitor viewing was not offered to patients when it came to injecting local anaesthetic, the biopsy or the loop excision. It was interesting to watch how easily the diathermy melts painlessly through the soft cervix. I detected the strange smell of the procedure. Each patient was given an instruction sheet about what had been done and exactly what the followup arrangements would be. Those who smoked were told to try to stop on the grounds of the latest evidence on healing and immunity to infection.

Thursday I spent an hour sitting in with Mr Higginson at the trauma clinic. By this I mean sitting, standing, walking and running after this inspiring personality who worked at top speed. Consulting room doors seemed to be kept open for ease of access and there seemed to be a patient in every little room, awaiting some procedure or advice. GP letters were dictated in a matter of seconds after every patient contact. It is a long time since I did any orthopaedics,

but in one hour I saw a patient with Perthe's disease, clavicle fractures, lunate injuries, avascular necrosis, a patient recovering from a crush injury when his right arm became caught between rollers at work, a lady recovering from having accidentally impaled her hand on a carving knife in her kitchen drawer, the aspiration aspiration of syringe-full of green pus from a lady's septic shoulder, a teenager with an ankle injury still insisting on red handled pliers wearing Spice Girl-style very high heeled boots costing $£ 80$ (the same cost as the Dexa scan), several boys who had 'falling off bike' injuries, various broken arms being plastered, and the removal of a wire from a man's wrist by Mr Higginson, using a pair of red-handled pliers. 
In the afternoon I went to the rheumatology clinic in Kendal. Dr Wendy Dodds was welcoming and I noticed she was wearing a pendant resembling a small femur ( I may be wrong as anatomy is not one of my strengths) with a pen slotted in the proximal end. I saw a patient with wrist pain having a steroid injection, the examination of a patient with cervical spondylosis and another with ankle pain (we discussed plantar fasciitis and the provision of night tension splints). I felt that this outpatient session, of all I had seen so far, most resembled my own consultations and the type of patients who presented, and I realised that this was a subject in which I really needed more tuition as part of my future continual personal learning programme.

Friday In the morning I went to nuclear medicine and was shown to the radio-isotope department.

There were five patients in a minute waiting area. One

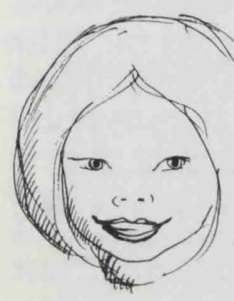
patient was doing all the talking and telling the others about the snow of 1947. A Danish nurse was accompanying one of the ward patients. I met the radiographers who told me how the radio-active material is ordered in advance on a named-patient basis and is very expensive; therefore, if a patient fails Danish nurse to arrive for the test the material is returned to Manchester. It cannot be

reused, and is wasted.

Jane Hall, the radiographer, told me about perfusion scans, which are a particulate injection. I watched one of these intravenous injections - they are brilliant at it, especially as the syringe is encased in a heavy leaded sleeve. After the injection the patient is allowed to go home or out of the department for two hours before returning for the actual scan. We discussed the scans performed in the department: bone, lung and kidney, left ventricular ejection fractions, MUGA scans, thyroid, parathyroid, gastric emptying and biliary scans.

I noticed patients wearing gowns with tiny words about this size: HOSPITAL PROPERTY printed all over in pastel shades. I watched a renal perfusion scan being done. The patient had to lie still on a very narrow couch reminiscent of a school bench, and the scanning took 45 minutes. The radiographer was in the room with the patient all the time. It was a strange piece of equipment; some parts of it had to be changed in position between patients. This involved heavy lifting by two radiographers. I realised they need strong arms as well as all their other skills.

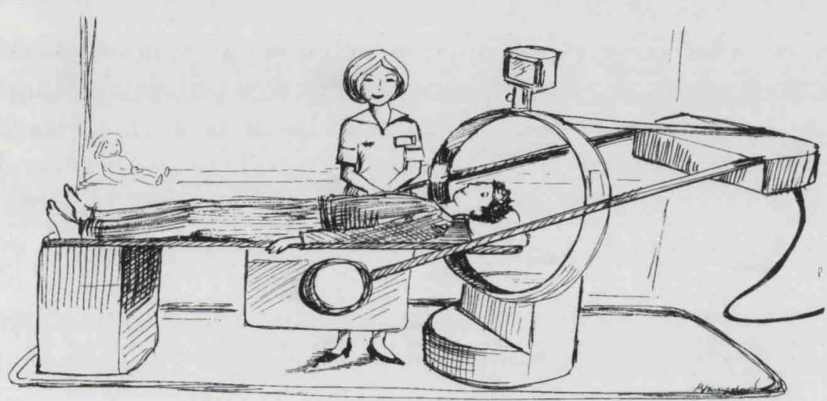

the patient had to lie still
In the ultrasound department I watched Dr Ness at work. The modern-looking and expensive ultrasonic equipment virtually fills the room. There is just room for the patient on the couch, the radiologist and one other, so I was very close to the patient and the monitor. I watched a lady with abnormal gynaecological bleeding having a uterine scan and a terminally ill patient who had come in by ambulance from the hospice - she had gross ascites from secondary ovarian cancer. The scan was requested so that the radiologist could make a mark on her abdomen as to the safest place to insert a tap for draining the ascites. Unfortunately the liver was so large that there was hardly any safe place.

Ultrasound images are very perplexing for the inexperienced, but with help, some things become visible.

On the Friday afternoon I went to medical outpatients. I arrived early and sat down just next to a clinical-looking trolley containing all the equipment used for sigmoidoscopy. It would have been a good start for nervous patients. Things like this will be a thing of the past now the new outpatients department is open. The walls are not so thin that waiting patients can hear consultations despite the piped music.

I was made welcome by Dr Colin Brown. Friday afternoons cannot be the ideal time for a busy clinic when you need to sort out problems. I learned about gluten- and lactose-free diets, malabsorption syndrome and steatorrhoea and coeliac disease and irritable bowel syndrome (a number of patients came in with this as a diagnosis). The current waiting times are 12 weeks for a barium enema and six weeks for colonoscopy.

I observed two consultations that involved the breaking of bad news. One was an elderly man with secondary cancer from an unknown primary, the other a younger man so ill and in pain that he agreed to immediate admission. It is not easy to give bad news but it was taken slowly and with gentleness. I sat still and silent and watched it all.

\section{CONCLUSION}

When I look back at my original aims, I still need further help with diabetes, ACE inhibitors and rheumatology, but I have achieved far more than I expected in just one week. Devising my own education plan worked well for me, and my patients have benefitted from my increased confidence in the areas that I studied. The experience, however, has uncovered more gaps in my knowledge. I am planning to repeat it as part of a continual personal education plan. What I also wonder is - do the consultants I met during my week in hospital fancy a week spent at a Lancaster general practice only a short walk across the road?

\section{Acknowledgements}

I wish to thank all the people who helped me with this work. Dr Flanagan encouraged me to try it out and colleagues gave access to the various departments. Thank you to all the patients who kindly allowed me to observe them whilst they were having their diagnostic procedures.

All pictures were drawn by the author, and those of patients are imaginative and not intended to resemble any patients seen during the week. 